Mini Review

\title{
Unheard \& Ignored: Impacts of COVID-19 Lockdown on Disadvantaged Children in Nepal
}

\author{
Akash Pandey $^{1 *}$, Ashmita Lama ${ }^{2}$, Aassmi Poudyal ${ }^{3}$ \\ ${ }^{1}$ Department of Social Work, Tribhuvan University, K \& K International College, New Baneshwor, Nepal \\ ${ }^{2}$ University of New Haven, Connecticut, USA \\ ${ }^{3}$ Department of Pathology, Civil Service Hospital, New Baneshwor, Nepal
}

\section{Article Information}

Received: 10 July 2021

Revised version received: 13 October 2021

Accepted: 16 October 2021

Published: 29 October 2021

Cite this article as:

A. Pandey et al. (2021) Int. J. Soc. Sc. Manage.

8(4): 432-437. DOI: 10.3126/ijssm.v8i4.38694

\section{*Corresponding author}

Akash Pandey,

Department of Social Work, Tribhuvan University, K \& K International College, New Baneshwor, Nepal

Email: akaspandey.sw@gmail.com

Peer reviewed under authority of IJSSM

(C) 2021 IJSSM, Permits unrestricted use under the CC-By-NC license.

\section{OPEN 0 ACCESS}

This is an open access article \& it is licensed under a Creative Commons Attribution Non-Commercial 4.0 International

(https://creativecommons.org/licenses/by-nc/4.0/)

Keywords: Disadvantaged children; COVID-19; Lockdown

\begin{abstract}
The unprecedented situation brought by the COVID-19 lockdown has affected lives across the world. Although the effects of pandemic on children are less heard and often ignored, it will have a ripple effect on their well-being specifically those from disadvantaged backgrounds including street childrens, children with disabilities and children from marginalized communities. The study was conducted using secondary data employing a descriptive method to analyze the issue comprehensively. It has conducted an extensive literature review of the past and present situation of those children and has outlined the possible repercussions that the current crisis may trigger. Different factors such as job loss, family debts, school closure, domestic violence, and economic burden are found to intensify thecurrent problems faced by disadvantaged children in Nepal. Findings show that thecurrent effect of COVID-19 can have an intergenerational impact, undermining thewellbeing of both present and future lives. The study suggests undertaking primary research to highlight the problems from a much broader way so that the results can be implicated more scientifically to grab the attention of policymakers and other relevant stakeholders to address the issue.
\end{abstract}

\section{Introduction}

According to UNICEF, globally $99 \%$ of children and young people under the age of 18 resides in one of the 186 countries with the status of movement restrictions and $60 \%$ of all children live in one of the 82 countries having full (7\%) or partial $(53 \%)$ lockdown which constitute 1.4 billion young lives (UNICEF, 2020a). Nepal started it's full lockdown on 24th March and extended it until 14 June (Mahato et al., 2020) and currently, the second wave is in effect. Although the lockdown has affected the lives of all sections of society, children with special abilities, street children, and marginalized communities' children are often highly vulnerable to the dire consequences of the lockdown. 
Due to the effect of a global pandemic, an additional 142 million children in developing economies are approximated to be under the household's poverty line as projected by the UNICEF (2020b). Likewise, UNICEF also calculated 150 million increases in a number of children living in multidimensional poverty without access to basic needs such as education, health care, housing, nutrition, or water. According to UNICEF (2020c) 10 million children in Nepal are estimated to be poor and this number of children are expected to face the terrible effects of COVID-19 lockdown. With the closure of the school, at least a third of the world's and two-thirds of Nepal school children mostly from rural areas and poorest households were unable to access remote learning (UNICEF, 2020d). The immediate effect of school closure has led to an increase in child marriage, abuse, child labour, and school dropout. In a recent report published by UNICEF (2021a), 4.5 million girl's child population in South Asia including Nepal are never likely to return to school. A survey conducted by an international non-governmental organization i.e. Voluntary Service Overseas (VSO) found that 11 out of 152 girls had been married in the four districts amidst the lockdown (Logan \& Maharjan, 2020). In a recent household survey undertaken by UNICEF (2021b) covering $85 \%$ of municipalities across Nepal, $5 \%$ of respondents reported noticing an increase in violence towards children in their communities, and from the same study, it was found that the disruption of family income plunged $24 \%$ of children into labour to support family livelihood. Besides, problems faced by children with disabilities and street children have been often ignored in the current context. UNICEF (2020e) reports that the lockdown has a disproportionate impact on children with disabilities. Human Rights Watch in 2011 has estimated around 207,000 children with disabilities in Nepal (Human Rights Watch, 2018). During the COVID-19 lockdown, children with disabilities were deprived of education and often susceptible to abuse and exploitation. Under with the study led by World Bank (2020), 50\% of schools in Nepal were providing some form of remote teaching support to children with disabilities. A study led by Save the Children found that $90 \%$ of the caregivers of children and young people with disabilities reported encountering obstacles to learning (Fernandez, 2021). In the case of street children, the pandemic has halted their survival activity leaving them with no alternatives to survive and almost no access to knowledge on preventive measures of COVID-19, making them vulnerable to getting infected. With all these concerns, this study has been initiated to explore the impacts of COVID-19 lockdown on disadvantaged childrens with specific focus on examining the problems faced by the target group and shed light on how these identified problemsmay trigger future consequences in their lives.

\section{Rise in Street Children}

Existing literature shows that there is no reliable data on street children in Nepal. However, street children living and working on the streets of Nepal are approximated to be 5,000 (Sharma, 2020). Koirala, 2020 asserts that at whatever time such as insurgencies, wars, disasters, epidemics, and pandemics took place, records show they resulted in a rise in the number of homeless children. For instance, the aftermath of the 2015 earthquake in Nepal killed over 9000 people and destroyed more than 700000 homes leaving millions homeless including children (Shaw, 2017). Likewise, the outcome of the COVID-19 lockdown can also possibly lead to an increase in the number of street children in Nepal. With the nationwide closure, people from marginalized communities whodepend primarily on daily wages or unskilled labour are facing difficulty to run their daily livelihood. The study conducted by UNDP (2020) titled "Rapid Assessment of the Social and Economic Impacts of COVID-19 on the vulnerable groups in Nepal" has indicated that three in fiveemployees have lost their jobs in micro and small businesses whereas the seasonal and informal workers whorepresent 60 percent of the labour force face job cuts and losses. Out-turn of household economic disruption can trigger family violence at a maximum which can hamper children's mental state and overall development. Asa result, children may end up in the street. It is because numerous studies in the past have found family violence as the leading cause of pushing children towards street life.

\section{Rise in Trafficking}

Despite the global pandemic of COVID-19, issues of child trafficking continue to increase in Nepal. According to Mandal (2019), the annual report of the human rights body revealed that nearly 35000 Nepalese citizens were trafficked to different global destinations in 2019 of which 5000 were noted as children only. Those who were trafficked were generally from poor and marginalized communities. There is a high possibility that the COVID19 lockdown can double the rate of child trafficking in Nepal as doors for traffickers have been escalated by the COVID, so children may possibly end up in their hands because of the hope of getting attractive jobs and opportunities. Also, during such crisis, children remain the primary hope for poor families. At the period of drafting this article, the National Human Rights Commission (NHRC, 2021) estimated that around 1.5 million Nepalese are susceptible to multiple forms of human trafficking of which child laborers, girls, and women from rural areas were pointed to as most vulnerable (Mandal, 2019).

\section{Increase in Dropout Rate}

Having previously been affected hugely by the earthquake of 2015, the COVID-19 lockdown has posed an extra risk in the education sector of Nepal. With almost five months 
of a nationwide closure of schools, there is a high prospect that the pandemic can upsurge the cases of dropout particularly students/children from vulnerable communities are at more risk. In fact, it has impacted children from poor families disproportionately. While the private education institutions initiated virtual modality, students having access to electronic devices and the internet are able to continue their classes, however, students from back warded regions and government schools with poor socio-economic backgrounds, problems of electricity, and low proficiencies in English and technological skills are unable to participate in online and distance education (Devkota, 2021). The inability to involve in online classes and the lack of inclusion in the alternative education system are likely to be the reasons for children dropping out of school. As the pandemic pushes more people into poverty, the closed classrooms can leave children exposed to labour works to support their family livelihood UNICEF (2020f). A survey conducted by the organization Room to Read found that $53 \%$ of female students may not go back to school when they reopen as they will be found helping their families to overcome the financial hardships (Sharma, 2020). Thus, two-thirds of school children in Nepal were unable to access remote learning amidst lockdown as revealed by UNICEF (2021i). Therefore, chances are at a maximum that the COVID-19 lockdown can further soar the rate of dropout in Nepal.

\section{Rise in Child Labour}

Since 2000, the rate of child labour was reduced by 94 million across the world. However, the recent report published by UNICEF (2020f) has indicated that the pandemic can push millions of children into child labourand Nepal is no exception. In Nepal, ILO (2021) revealed 1.1 million children between 5 and 17 years of age to be engaged in various forms of child labour. While this is a significant drop in comparison to previous years, the COVID-19 can give rise to additional numbers. A study conducted by UNICEF (2020f) revealed that 1 billion learners in over 130 countries including Nepal affected by the temporary closures of schools. Even, when the school reopens, families affected by the COVID-19 may not be able to afford their children to send to schools because of loss of income and indebtedness. The immediate result of these issues can uptick the existing rate of child labour in Nepal as children become the coping mechanism for poor families in the times of crisis. For example, when Nepal was struck by the 7.8 magnitude earthquake in 2015, tens of thousands of homes were destroyed and livelihoods disrupted leaving 1.1 million children at risk of labour as families struggle to care for them (KC, 2016). Besides, the rising level of domestic violence, abuse and exploitation faced by children can also push them towards street life, where they might engage in economic activity such as rag picking, conductors, brick kilns, etc.

\section{Rise in Child Abuse}

Previous studies show that children are more likely to experience abuse and exploitation during a time of crisis. Although child maltreatment can occur with any children in the form of sexual, physical, emotional abuse, negligence, and other exploitations, children particularly disabled and underprivileged are most vulnerable to abuse. UNICEF (2020e) estimated about 5.1 million children living with disabilities worldwide are highly at risk from all forms of abuses amid the unprecedented situation of COVID-19 lockdown. In Nepal, all schools for children including an institution for special needs, including day-care centershave been closed since mid-April (Taylor, 2021), leaving children with the abusers mostly entrusted to care of them such as family members, without the safe space that school would normally offer. A recent global study approximated that 30 percent of the abusers are relatives of the child most often brothers, fathers, uncles, or cousins (Uprety, 2019). Children having extensive access to the internet may have exposure to abusive online content and social media like Facebook which can leave them in the hands of abusers. Mounting of unemployment rate resulting from COVID-19 lockdown has pushed destitute more towards poverty so, probability is at maximal that the rate of child abuse can rise significantly. It is because, at whatever time, families' experiences economic instability, ill-treatment of child was at the peak. For example, because of the drinking and hitting behavior of returnee migrant workers amidst the pandemic, 39 cases of domestic violence with children and women were recorded in Achaam only (Dhungana, 2020).

\section{Rise in Child Marriage}

UNICEF has estimated a spike in the rate of child marriage by an additional 10 million before the end of this decade (Sharma \& Gettleman, 2021). Nepal, having the thirdhighest rate of child marriage after Bangladesh and India is also further expected to suffer due to the COVID-19 pandemic. As the current situation has created financial stress in poor families, children are often considered as a burden and as a matter of fact, they let their children to reduce their difficulty. For example, the repercussion of the earthquake 2015 in Nepal created economic pressure on people that led to the rise of child marriage dramatically. (Logan \& Maharjan, 2020). Child marriage in Nepal is often taken as an integral part of people's culture, therefore, despite the fear of a pandemic, people may have forced their children to marriage to give continuity to their lifelong ancestor's tradition. Having said that, 169 incidents of child marriage were reported in Kalikot district only during the pandemic (Pandey, 2021) and thirty cases were recorded in one municipality of Sarlahi district (Logan \& Maharjan, 2020). So, with these understandings, doors for child marriage have been further intensified by the COVID, which does not only affect the children's present life but overall multi-generational structure. 


\section{Psycho-Social Problems}

Distressing situation created by the COVID-19 lockdown has impacted the mental health of children across the globe. In research from UNICEF (2020g), 1 in 7 children and young people have spent the 2020 year staying at home. As children require an open environment to play, learn, interact and grow, lockdown has disrupted these development activities posing a greater risk in their psycho-social wellbeing. Peculiarly, the adverse impact can be largely observed in children having pre-existing problems of psychiatric disorders such as behavior and mood disorders, hyperactivity, etc. (Shah et al., 2020), and those living under poverty without proper access to social support (Poudel, 2020). With the closure of child care centers, children with special abilities have long remained under the guidance of parents, who might lack prior knowledge to manage them and can cause them to cultivate a feeling of loneliness, helplessness, and isolated. Likewise, children's inability to cope up with a tragic situation such as parent's deaths, income loss, family burdens, and abuses might also take them to the depths of depression, anxiety, and delusion. Nevertheless, without the utmost family care and freedom to play, socialize and participate in circles and extracurricular, children can get frustrated and indulge in activities such as watching TV, and Internet (Budhathoki, 2020). This can ultimately make them idle and unproductive.

\section{Vulnerability to Infection}

To prevent the spread of the COVID-19 pandemic, several educational campaigns were organized by municipal bodies across Nepal with the message of "stay home, stay safe". People owing shelter have been able to protect themselves by following safety precautions such as washing hands and taking healthy foods. But those without roofs and foods are especially susceptible to the COVID-19 infection. This includes street children and homeless people. The Human Development Report published by UNDP shows that 250,000 people are homeless in Nepal (Kim, 2015) and the number of street children was estimated to be 5000 by CWIN Nepal (2018). Having been already ignored by the state, the status of these backgrounds is often unknown amidst the pandemic in terms of COVID-19 infection i.e. how many of them get infected and how many deaths? Inaccessibility to safety materials such as masks, sanitizer, awareness, and huge queueing for foods has posed risk in them from getting infected. Even some of them may have get exposed but lack of knowledge regarding preventive measures, government support, and financial hardships has kept them under silence. On this note, unless these problems are unidentified, they continue to remain unsafe from COVID-19.

\section{Vulnerability to Hunger}

According to new research conducted by UNICEF (2020h), 6 to 7 million children under age 5 mostly from Sub-Haran Africa and South Asia are approximated to be additional victims of acute malnutrition. Nepal, having already about $43 \%$ malnourishment rate will also see an increment according to a recent survey conducted by UNICEF (2021b) entitled "Tracking the Socio-Economic of COVID-19 on Children and Families". Children who were getting meals in schools have been missing out on the provided complemental due to the closure of the school forthe past 5 months and families facing job loss have been undergoing shortages of alimentary foods such as meats, milk, and vegetables (Nepali Times, 2020). Although the government of Nepal announced a relief package to assist the most vulnerable, its accessibility was daunting due to slow-paced procedures and the inability to identify the actual needy, which have directly or indirectly affected child health and dietary habits. In terms of children living inthe street, the disturbance in their survival activity such as begging or ragpicking has affected their livelihood and their condition whereabouts are unknown. Some group of kindly hearted person has been found distributing foods to them and few news of government-led rescues were heard. Despite these, they remain to suffer from hunger as the prolonged lockdown continues to obstruct their day-to-day living activities.

\section{Conclusion}

To conclude, children from disadvantaged backgrounds continue to remain vulnerable to a multitude of problems in the midst of COVID-19 lockdown in Nepal. Studies reveal that children with special abilities, street children, and those living under poverty are primarily impacted by the lockdown. Having been enduring several problems, the COVID-19 has added an extra burden into their life. Thus, the study concludes with an urgency to conduct primary research to highlight the bleak picture of the target group extensively so that the results can be implicated in a much scientific manner to wake up the so-called policymakers and other relevant stakeholders to address theissue.

\section{Authors' Contribution}

All authors contributed equally in the all stages of this work. Final form of the manuscript is approved by all authors.

\section{Conflict of Interest}

The author declares no competing interests with the present work.

\section{References}

Adhikari P (2020, June 30). Aren't children the masked victims of COVID-19? The Himalayan Times. Retrieved from: https://thehimalayantimes.com/opinion/arent-childrenthe-masked-victims-of-covid-19 
CWIN (2018) Street children in Nepal. Retrieved from: http://www.cwin.org.np/phocadownloadpap/fact_sheets/s treet\%20children.pdf

Devkota KR (2021) Inequalities reinforced through online and distance education in the age of COVID-19: The case of higher education in Nepal. International Review of Education 3:1-21.

Dhungana M (2020, September 21). Cases of violence against women have gone up in Achham. The Kathmandu Post. Retrieved from:

https://kathmandupost.com/sudurpaschimprovince/2020/09/21/cases-of-violence-against-womenhave-gone-up-in-achham

Fernandez RC (2021) Children with disabilities can learn and the pandemic should be no barrier. Retrieved from: https://gemreportunesco.wordpress.com/2021/05/05/child ren-with-disabilities-can-learnand-the-pandemic-shouldbe-no-barrier/

Human Rights Watch (2018) Nepal Barriers to inclusive education. Retrieved from: https://www.hrw.org/news/2018/09/13/nepal-barriersinclusive-education\#

ILO (2021) Child labour rises to 160 million - first increase in two decades. Retrieved from: https://www.ilo.org/kathmandu/info/public/pr/WCMS_80 1338/lang--en/index.htm

KC S (2016, July 28). Child labour: Learn from others. The Himalayan Times. Retrieved from: https://thehimalayantimes.com/opinion/child-labourlearn-others

Kim W (2015) Safe havens: Why homelessness and slums make LVA important. Children \& Youth First. Retrieved from: http://cyfnepal.org/cyf-blog/2015/6/30/safe-havens-whyhomelessness-and-slums-make-lva-important

Koirala U (2020, June 16). This is how covid-19 will increase street children's number in Nepal. Online Khabar English News. Retrieved from: https://english.onlinekhabar.com/this-is-how-covid-19will-increase-street-children-number-in-nepal.html

Logan M \& Maharjan SS (2020). Nepal child marriages spike during pandemic. Nepali Times. Retrieved from: https://www.nepalitimes.com/latest/nepal-childmarriages-spike-during-pandemic/

Mahato P, Tamang P, Simkhada P, Shahi, P, Teijlingen EV, Aryal N, \& Regmi P (2020) Effects of COVID-19 during lockdown in Nepal. Europasian Journal of Medical Sciences 2(2):105-110.

Mandal CK (2019, August 6). Nearly 1.5 million Nepali at risk of human trafficking while 35,000 trafficked last year: NHRC report. The Kathmandu Post. Retrieved from: https://kathmandupost.com/national/2019/08/06/nearly-15-million-nepali-at-risk-of-human-trafficking-while-35000-trafficked-last-year-nhrc-report

Nepali Times (2020). COVID-19 impact on food and school in Nepali children. Retrieved from: https://www.nepalitimes.com/latest/covid-19-impact-onfood-and-school-in-nepali-children/

Pandey T (2021, March 14). In Kalikot district, incidents of child marriage are still rampant. The Kathmandu Post. Retrieved from: https://kathmandupost.com/karnaliprovince/2021/03/14/child-marriage-still-unchecked-inkalikot

Poudel A (2020, May 12). Prolonged lockdown can have a lasting impact on children's mental wellbeing, psychologists say. The Kathmandu Post. Retrieved from: https://kathmandupost.com/health/2020/05/12/prolongedlockdown-can-have-a-lasting-impact-on-children-smental-wellbeing-psychologists-say

Shah K, Mann S, Singh R, et al (2020) Impact of COVID-19 on the Mental Health of Children and Adolescents. Cureus 12(8): e10051.

Sharma B, \& Gettleman J (2021, March 8). Child marriage is rising in Nepal and around the world. The New York Times. Retrieved from: https://www.nytimes.com/2021/03/08/world/asia/childmarriage-nepal-covid19.html

Sharma MK (2020) Street children in Nepal: Causes and health status. Journal of Health Promotion, 8, 129-140.

Sharma N (2020). Half of Nepal's girls may drop out of school. Nepali Times. Retrieved from: https://www.nepalitimes.com/latest/half-of-nepals-girlsmay-drop-out-of-school/

Shaw S (2017, April 27). Exploiting Nepal's children. The Diplomat. Retrieved from: https://thediplomat.com/2017/04/exploiting-nepalschildren/

Taylor M (2021, May 4). The pandemics disproportionate effect on children with developmental disabilities. The Record. Retrieved from: https://www.recordnepal.com/thepandemics-disproportionate-effect-on-children-withdevelopmental-disabilities

UNCHS Habitat (2000) Strategies to Combat Homelessness. UNHabitat. Retrieved from: https://unhabitat.org/strategiesto-combat-homelessness

UNDP (2020) Three in five employees lost their jobs due to COVID-19 in Nepal. Retrieved from: https://www.np.undp.org/content/nepal/en/home/presscen ter/articles/2020/Three-in-Five-employees-lost-theirjobs-due-to-COVID19-in-Nepal.html

UNICEF (2020a) Don't let children be the hidden victims of COVID-19 pandemic. Retrieved from: https://www.unicef.org/nepal/press-releases/dont-letchildren-be-hidden-victims-covid-19-pandemicunicef

UNICEF (2020b) COVID-19 and children. Retrieved from: https://data.unicef.org/covid-19-and-children/

UNICEF (2020c) Number of children living in household poverty to soar by up to 86 million by end of year. Retrieved from: https://www.unicef.org/nepal/press-releases/covid-19-

Full text of this paper can be downloaded online at www.ijssm.org/ \& http://nepjol.info/index.php/IJSSM/issue/archive 
number-children-living-household-poverty-soar-86-

million-end-year

UNICEF (2020d) At least a third of the worlds and two-thirds of Nepal's school children unable to access remote learning during school closures. Retrieved from: https://www.unicef.org/nepal/press-releases/covid-19least-third-worlds-and-two-thirds-nepals-schoolchildrenunable-access

UNICEF (2020e) Protecting children and adolescents with disabilities from the pandemic. Retrieved from: https://www.unicef.org/eca/protecting-children-andadolescents-disabilities-pandemic

UNICEF (2020f) COVID-19 may push millions more children into child labour. Retrieved from: https://www.unicef.org/nepal/press-releases/covid-19may-push-millions-more-children-child-labour-ilo-andunicef

UNICEF (2020g) At least 1 in 7 children and young people globally has lived under stay-at-home policies for most of the last year, putting mental health and well-being at risk. Retrieved from: https://www.unicef.org/thailand/pressreleases/least-1-7-children-and-young-people-globallyhas-lived-under-stay-home-policies-most

UNICEF (2020h) How the COVID-19 pandemic has scarred the world's children. Retrieved from:
https://www.unicef.org/coronavirus/COVID-19-

pandemic-scarred-world-children

UNICEF (2020i) COVID-19: At least a third of the world's and two-thirds of Nepal's schoolchildren unable to access remote learning during school closures, new UNICEF report says. Retrieved from: https://www.unicef.org/nepal/press-releases/covid-19least-third-worlds-and-two-thirds-nepals-schoolchildrenunable-access

UNICEF (2021a) Disruptions in health services due to COVID-19 may have contributed to an additional 239000 child and maternal deaths in south Asia. Retrieved from: https://www.unicef.org/rosa/press-releases/COVID-19Modelling-Report-Launch

UNICEF (2021b) Tracking the socio-economic impact of COVID19 on children and families in Nepal. Retrieved from: https://www.unicef.org/nepal/media/9451/file/COVID19_Child_and_Family_Tracker.pdf

Uprety A (2019, February 1). A child cries in silence: Sexual abuse widespread. The Himalayan Times. Retrieved from: https://thehimalayantimes.com/opinion/a-child-cries-insilence-sexual-abuse-widespread

World Bank (2020) Making learning accessible to all in Nepal. Retrieved from: https://blogs.worldbank.org/endpovertyinsouthasia/makin g-learning-accessible-all-nepal 